
\title{
25 Research Square \\ The Economic Burden of Coronavirus Disease 2019 (COVID-19): Evidence from Iran
}

\section{Mohsen Ghaffari Darab}

Shiraz University of Medical Sciences

Khosro Keshavarz

Shiraz University of Medical Sciences

\section{Elnaz Sadeghi}

Shiraz University of Medical Sciences

Javad Shahmohamadi

Shiraz University of Medical Sciences

Zahra Kavosi ( $\nabla$ zhr.kavosi@gmail.com )

Shiraz University of Medical Sciences https://orcid.org/0000-0001-8662-7987

\section{Research}

Keywords: COVID-19; Coronavirus; Economic burden; Health policy; Hospital costs; Intensive care units; cost-of-illness; Iran.

Posted Date: August 21st, 2020

DOl: https://doi.org/10.21203/rs.3.rs-60500/v1

License: (c) (i) This work is licensed under a Creative Commons Attribution 4.0 International License. Read Full License 


\section{Abstract}

This study aimed to estimate both direct medical and indirect costs of treating the Coronavirus disease 2019 (COVID-19) from a societal perspective in the patients at a referral hospital in Fars province as well as the economic burden of COVID-19 in Iran in 2020.

\section{Methods:}

This is a partial economic evaluation and a cross-sectional cost-description study conducted descriptively-analytically and based on the data of the COVID-19 patients referred to a referral university hospital in Fars province between March and July 2020. The data were collected by examining the patients' records and accounting information systems. The subjects included all the inpatients with COVID-19 (477 individuals) who admitted to the medical centre during the four months. Bottom-up costing, incidence-based and income-based human capital approaches were used as the main methodological features of this study.

\section{Results:}

The mean direct medical costs were estimated $28,240,025,968$ Rials $(\$ 1,791,172)$ in total and $59,203,409$ Rials $(\$ 3,755)$ per person, a significant part of which $(41 \%)$ was that of intensive and general care beds $(11,596,217,487$ Rials equal to $\$ 735,510$. (The second to which were the costs of medicines and medical consumables $(28 \%)$. The mean indirect costs including income loss due to premature death, economic production loss due to hospitalization and job absenteeism during recovery course were estimated $129,870,974$ Rials ( $\$ 11634$ ) per person. Furthermore, the economic burden of the disease in the country for inpatient cases with the definitive diagnosis was $22,688,925,933,095$ Rial equal to $\$ 1,439,083,784$.

\section{Conclusion:}

The results of this study showed that the severe status of the disease would bring about the extremely high cost of illness in this case. It is estimated that the high prevalence rate of COVID-19 has been imposing a heavy economic burden on the country and health system directly that may result in rationing or painful cost-control approaches.

\section{Introduction}

The novel coronavirus disease, currently known as Coronavirus disease 2019 or simply COVID-19 (caused by the SARS-CoV-2 pathogen), was first introduced as an epidemic in December 2019 in Wuhan, Hubei, China $(1,2)$. It was increasingly spread in many countries on all five continents of the world, with the World Health Organization announcing in March 2020 that the COVID-19 pandemic was one of the health issues raising international concern(3). The WHO also called for early diagnosis, isolation and treatment of the patients, contact tracing, and social distancing in order to break the chain of virus transmission (4). 
According to the statistics published on the worldometers database, more than $16,433,715$ million people in the world had been infected with COVID-19 by July 2020, of whom over 652,454 individuals have lost their lives. The information of this database also showed 291,172 and 15,700 for these two figures about Iran, respectively (5). Transmission of the virus through respiratory droplets has caused the disease to spread rapidly and infect many people (6). Individuals with a mean age of 55.5 years (7) and those with underlying diseases, such as hypertension, diabetes, and heart disease, are at a higher risk $(8,9)$. Thus, the health status of the elderly and those with underlying diseases are twice as much important because demand aggregation followed by the collapse of the health system may prevent the provision of routine medical services to the people in need. For example, modelling studies by the World Health Organization showed that stopping the provision of antiretroviral therapy services in the Sub-Saharan could lead to an additional 500,000 AIDS-related deaths $(10,11)$.

From an economic perspective, the spread of COVID-19, the ever-increasing number of patients, and the complications of the disease have imposed significant direct medical and indirect costs on patients, the health system and the government (12). As far as the economic burden of direct medical costs is concerned, although the costs vary with the number of the infected people, the severity of the disease, mean length of stay in the hospital, mean length of stay in the ICU, and other factors $(13,14)$, international studies showed that medical costs of the patients with COVID-19 were significantly higher than those of other infectious diseases due to the higher probability of hospitalization and mortality (15). This is true about the need for COVID-19 patients for special care services and the related costs (16-18). Statistics have shown that $3 \%$ of the people with COVID-19 in the world are in critical condition and need special care services (5). The results of a study on 138 individuals with COVID-19 in Wuhan, China, indicated that $26.1 \%$ of the patients used special care services, of whom $41.6 \%$ and $47.2 \%$ received non-invasive and invasive ventilation, respectively (19). In Lombardy, Italy, $88 \%$ of the patients admitted to the ICU received invasive ventilation and $11 \%$ received non-invasive one (20). While the daily cost of hospitalization in the ICU is generally 3-4 times higher than in general wards (21).

Moreover, the lost income due to the disease or mandatory stay at home or the death of the workforce due to the disease could be considered as indirect costs (22-24). The prevalence of COVID-19 and closure of many industries would reduce Gross Domestic Product $(\operatorname{GDP})(25,26)$. According to studies, the global spread of the disease will lead to a decrease in global GDP by $2.5-3 \%$ per month (27). Furthermore, the outbreak of COVID-19 severely damaged the world's top fifteen economies (28). Comparing the economic effects of this disease with those of past epidemics shows that the economic crisis facing the world is much more serious than what was experienced in the past.

Therefore, regarding the high costs of the treatment of the patients with COVID-19 and its resulting economic burden on the health system and the country generally, and due to the upcoming economic crisis, it seems important to calculate direct medical and indirect costs of treatment of the disease.

\section{Methods}


This applied research is a partial economic evaluation and a cross-sectional cost-description study conducted descriptively-analytically within the period. The research population consisted of all the patients with COVID-19 who had referred to the main referral medical centre for the treatment of COVID19 patients in Fars province, Iran by July 2020. As the research sample was equal to the research population, no sampling was done and all the patients were examined through a census.

The inclusion criteria were definitive infection with COVID-19 based on diagnostic tests and having been undergone all the treatment processes from diagnosis to discharge at the Hospital. The patients whose part of the treatment process had been performed outside the Hospital and were referred to a rehabilitation centre or other hospitals were excluded from the study. The required data were collected through the forms designed in two sections: the patient's demographic information and characteristics, and cost information. Given that the present study was conducted from the society perspective, the costs included direct medical (DC) and indirect costs (IC).

The bottom-up method was used to calculate direct medical costs due to the lack of a proper and accurate database. In this costing method, the input costs per service were summed up. The incidence approach was also used to provide cost information (29). According to the principle on which up-to-date studies are based, disease-related costs should be attributed to the year when the flow of costs began. All costs include direct medical costs and productivity losses based on present-value and are attributed to the year in which the disease was diagnosed $(30,31)$. In this study, direct medical costs were classified into 11 categories as follows: the costs of special and ordinary beds, visits, counselling, nursing services, drugs and medical consumables, rehabilitation, dialysis, imaging, electrography, laboratory, and other services (including monitoring in non-intensive care units, compilation and prescription of therapeutic diets, cannula implantation for venous-venous-hemodialysis, blood and blood products transfusion, tracheal intubation, level-one critical care or triage, blood oximetry or continuous pulse oximetry, temporary catheter insertion into the bladder, and cold room ). The resources used to calculate the direct medical costs were based on the national tariffs of 2019.

In this study, the indirect costs were also investigated based on the income-based human capital approach and measured in two parts, including the wages that a patient loss due to absenteeism (hospitalization or home rehabilitation) and the productivity loss as a result of a patient's premature death at the ages of 15 to 65 . The lost productivity was considered zero for the individuals under the age of 15 and over 65 who were not economically productive.

The Forgone Labor Output (FLO) equation was used to calculate the potential economic production loss due to the premature deaths:

$$
\mathrm{P}_{1}=\sum_{i=1}^{N} \frac{W *(1+g)^{i}}{(1+r)^{i}}
$$


In this equation, $\mathrm{P}_{\mathrm{I}}$ is the current value of the predicted future income per workforce, $\mathrm{N}$ is the mean working years per person at the age of $\mathrm{i}, \mathrm{W}$ shows the mean current income per person, $r$ stands for the social discount rate, and $\mathrm{g}$ is the annual real income growth rate per person(32).

\section{Economic Burden:}

Total cost (direct medical costs + indirect costs) $\times$ estimated number of infected inpatient cases in Iran.

In order to estimate the total economic burden on the country, the total cost (total direct medical and indirect costs) for each patient was first calculated and then multiplied by the total number of cases with COVID-19 throughout the country (33).

Since the available data suggested that the disease lasted for an acute episode and less than thirty days, the discount rate was not applied; in addition, all the costs were calculated based on purchasing power parity (PPP) 2020, adjusted by, equivalent to 15766 Rial per 1 dollar (34).

\section{Results}

\section{3 - 1 Epidemiological findings}

Of the 477 patients studied, none of the patients was under 15 years old, $41 \%$ were $15-45$ years old, $38 \%$ were $45-65$, and $21 \%$ were 65 years or more; Among them, $56 \%$ were male and $44 \%$ were female.

(Table 1: Patients Demographic Information). Fever, muscle pain, cough and respiratory distress were the main signs and symptoms among the patients. Nearly half of the patients suffered from at least one of the underlying diseases diabetes, heart disease or hypertension. Oxygen saturation levels were below $93 \%$ in $41 \%$ of the patients. $4 \%$ received tracheal intubation. Moreover, $7 \%$ of the patients received ICU care due to a severe form of the disease.

Table 1

Patients Demographic Information

\begin{tabular}{|llll|}
\hline Gender & Variable & Total number & $\%$ \\
\cline { 2 - 4 } & Male & 266 & 56 \\
\cline { 2 - 4 } Age Groups & Female & 211 & 44 \\
\cline { 2 - 4 } & $0-15$ & 0 & 0 \\
\hline $15-45$ & 197 & 41 \\
\hline $45-65$ & 180 & 38 \\
\hline+65 & 100 & 21 \\
\hline
\end{tabular}




\section{$3-2$ Medical Direct Costs}

According to the results, the average medical direct costs were estimated $28,240,025,968$ Rials

$(\$ 1,791,172)$ per patient, in which intensive and general care beds expenses were the largest share of costs $(41 \%)$ with $11,596,217,487$ Rials equals to $\$ 735,510$. Following that, the main costs were those of medicines and medical consumables (28\%) with $8,044,070,257$ Rials equals to $\$ 510,209$ visits (12\%) $3,422,848,975$ Rials equal to $\$ 217,100$, and electrography and laboratory $(9 \%) 2,645,752,049$ Rials equal to $\$ 167,811$. Nursing and consulting services each one accounted for merely $2 \%$ of total costs (Table 2 : Medical Direct and Indirect Costs of studied patients).

\section{3- 2 Indirect Costs}

\section{3-2-1 Productivity loss due to Job Absenteeism}

Of the patients treated, $6.5 \%$ died; of these, $4 \%$ were in productivity age, who died an average of 11 years before age 65 . The results showed that the mean length of hospital stay for each COVID-19 patient was 7 days on average; with respect to this, the total lost income of a COVID-19 patient at the age of 15-65 due to hospitalization was estimated 5,950,524 Rials (equal to \$378) (According to the data of the Statistical Centre of Iran, the minimum monthly wage in 2019 was $24,000,000$ Rials, equal to the daily income of 800,000 Rials per individual).

In addition, based on the epidemiological data, a patient's lost income due to absenteeism during the recovery period of 21 days was estimated to be $16,800,000$ Rials (equal to $\$ 1065$ ) (Table 2: Medical Direct and Indirect Costs of studied patients). 
Table 2

Medical Direct and Indirect Costs of studied patients

\begin{tabular}{|c|c|c|c|}
\hline Medical Direct Cost & $\%$ & Total cost studied patients & Mean cost per patient \\
\hline \multirow[t]{2}{*}{ General and Intensive Care Beds } & 41 & $11,596,217,487$ (IR) & $24,310,728$ (IR) \\
\hline & & $735,510(\$)$ & $1,542(\$)$ \\
\hline \multirow[t]{2}{*}{ Visit } & 12 & $3,422,848,975$ (IR) & $7,175,784(\mathrm{IR})$ \\
\hline & & $217,100(\$)$ & $455(\$)$ \\
\hline \multirow[t]{2}{*}{ Consultant and surgeon } & 2 & $544,642,687(\mathrm{IR})$ & $1,141,809(\mathrm{IR})$ \\
\hline & & $34,545(\$)$ & $72(\$)$ \\
\hline \multirow[t]{2}{*}{ Nursing services } & 2 & $597,734,159(\mathrm{IR})$ & $1,253,111(\mathrm{IR})$ \\
\hline & & $37,912(\$)$ & $79(\$)$ \\
\hline \multirow[t]{2}{*}{ Drugs and supplies } & 28 & $8,044,070,257$ (IR) & $16,863,879$ (IR) \\
\hline & & $510,209(\$)$ & $1,070(\$)$ \\
\hline \multirow[t]{2}{*}{ Rehabilitation and Dialysis } & 1 & $358,674,154(\mathrm{IR})$ & $751,937(\mathrm{IR})$ \\
\hline & & $22,750(\$)$ & $48(\$)$ \\
\hline \multirow[t]{2}{*}{ Imaging } & 2 & $704,609,641(\mathrm{IR})$ & $1,477,169(\mathrm{IR})$ \\
\hline & & $44,691(\$)$ & $94(\$)$ \\
\hline \multirow[t]{2}{*}{ Electrography and Laboratory } & 9 & $2,645,752,049(\mathrm{IR})$ & $5,546,650(\mathrm{IR})$ \\
\hline & & $167,811(\$)$ & $352(\$)$ \\
\hline \multirow[t]{2}{*}{ Other services } & 1 & $325,476,558(\mathrm{IR})$ & $682,341(\mathrm{IR})$ \\
\hline & & $20,644(\$)$ & $43(\$)$ \\
\hline \multirow[t]{2}{*}{ Total } & 100 & $28,240,025,968$ (IR) & $59,203,409$ (IR) \\
\hline & & $1,791,172(\$)$ & 3,755 (\$) \\
\hline Indirect Cost & & & Mean cost per patient \\
\hline Lost income & & & $5,950,524(I R)$ \\
\hline (hospitalization) & & & $378(\$)$ \\
\hline Lost income & & & $16,800,000(\mathrm{IR})$ \\
\hline (recovery at home) & & & $1065(\$)$ \\
\hline Potential productivity Loss & & & $107,107,949$ (IR) \\
\hline (premature death) & & & $10,190(\$)$ \\
\hline
\end{tabular}




\begin{tabular}{|c|c|c|c|}
\hline Medical Direct Cost & $\%$ & Total cost studied patients & Mean cost per patient \\
\hline \multirow[t]{2}{*}{ Total } & & & $129,870,974(\mathrm{IR})$ \\
\hline & & & $11,634(\$)$ \\
\hline
\end{tabular}

\section{3-2-2 Production Loss due to Premature Death:}

Estimation of Potential Production Loss due to premature death followed a methodology previously described based on the Forgone Labor Output equation (Sect. 2: Method). Regarding this, average lost years was calculated 11 years based on deducing the age at death from expected working age (65 years) in patients between 15-65 years of age. Due to the lack of detailed wage information, the minimum annual wage was considered as the average income per capita in 2020 equal to 288,000,000 Rials (based on information from the ministry of cooperative labour and social welfare), and the annual growth rate for real income per capita (g) was considered 3 per cent. The discount rate also was set at 6 per cent. Finally, the economic loss caused by every premature death from COVID-19 estimated 2,677,698,726 Rials (equal to $\$ 169,838$ ).

$$
\mathrm{P}_{1}=\sum_{i=1}^{22} \frac{288,000,000 *(1+0.03)^{i}}{(1+0.06)^{i}}=2,677,698,726 \text { Rial }
$$

According to the mortality rate among hospitalized cases derived from the study, only $4 \%$ of this amount $(129,870,974$ Rials equal to $\$ 11,634)$ was considered in the calculation of the average indirect costs per inpatient.

Economic burden imposed on all inpatients with COVID-19 in Iran estimated 22,688,925,933,095 Rial equal to $\$ 1,439,083,784$ in the country based on the number of all inpatient cases equal to 120,000 individuals up until the end of July and the average cost of disease;

\section{Discussion}

This study was the first study on the cost of illness among COVID-19 patients in Iran. The outbreak of the COVID-19 and the increasing number of patients in Iran imposed heavy costs on the infected people and the health system. The economic burden of the disease in addition to the economic crisis facing the country caused concern among the managers and policy-makers in the health sector. Hence, identifying the economic consequences of the disease can be valuable evidence for policy-making.

The average direct medical costs for these patients were estimated to be $\$ 3,755$ per person. Based on a recent study in the United States conducted by Bartsch et al. the average direct medical costs per person were estimated $\$ 3,045$ throughout the period of the infection(15). In this regard, the results of these two studies are comparable. The results of this study also showed that this record of information varied with 
the severity of the disease. Critically-ill patients who received ICU services accounted for the largest share of direct medical costs. Although less than $7 \%$ of the patients with COVID-19 had received ICU services, they accounted for nearly one-fifth of the direct medical costs. Certainly, on average, patient care in intensive care units was 4 times more expensive than other patients.

The spread of the disease not only caused direct costs but also many indirect ones, including the potential production loss due to job absenteeism during hospitalization and recovery course at home, as well as production loss due to premature death. The productivity loss of the patients with COVID-19 was about two times more than the direct medical costs per patient on average.

According to the findings of this study, the median direct and indirect costs in total was $43,173,908,604,828$ Rial so far which was accounting for $1.5 \%$ of the average annual health expenditures in 2018.

\section{Research limitations and suggestions for future studies:}

Due to the limited access to demographic information of the individuals in this study, complementary investigation of the FLO in accordance with the individuals' income deciles was not carried out. In addition, due to the lack of information about underlying diseases, it was not possible to measure the related costs. Restrictions on social activities, including quarantine, social distancing, and lockdown, were among the unique features of the epidemic, which were directly associated with FLO. These factors are suggested to be taken into account when calculating indirect costs and direct non-medical costs including (including patient time, travel and out-of-pocket costs), in future studies.

\section{Conclusion}

Examining the economic dimensions of the disease through this research provided important evidence for making socioeconomic policies related to COVID-19 and similar epidemics. According to the results of this study, the high rate of pathogenicity, a considerable percentage of patients in need of intensive care and subsequently the huge costs of the disease (direct and indirect) can face the country's health system with unprecedented and significant economic stress in financing government and university medical centres. Thus, these centres might be forced to apply painful cost-control and rationing policies in providing the required care to this group of patients and others.

\section{References}

1. Lu H, Stratton CW, Tang YW. Outbreak of Pneumonia of Unknown Etiology in Wuhan China: the Mystery and the Miracle. Journal of medical virology.

2. Zhu N, Zhang D, Wang W, Li X, Yang B, Song J, et al. A novel coronavirus from patients with pneumonia in China, 2019. New England Journal of Medicine. 2020. 
3. Coronavirus disease (COVID-19) Pandemic - Emergency Use Listing Procedure (EUL) open for in vitro diagnostics: World Health Organisation; 2020 [cited 2020 cited4/17/2020]. Available from: https://www.who.int/diagnostics_laboratory/EUL/en/.

4. Coronavirus disease. 2019 (COVID-19): situation report, 72. 2020.

5. worldometer. [Internet]. 2020 [cited 04/06/2020]. Available from: .

6. Sabino-Silva R, Jardim ACG, Siqueira WL. Coronavirus COVID-19 impacts to dentistry and potential salivary diagnosis. Clinical Oral Investigations. 2020:1-3.

7. Chen N, Zhou M, Dong X, Qu J, Gong F, Han Y, et al. Epidemiological and clinical characteristics of 99 cases of 2019 novel coronavirus pneumonia in Wuhan, China: a descriptive study. The Lancet. 2020;395(10223):507-13.

8. Wu Z, McGoogan JM. Characteristics of and Important Lessons From the Coronavirus Disease 2019 (COVID-19) Outbreak in China: Summary of a Report of 72314 Cases From the Chinese Center for Disease Control and Prevention. Jama. 2020.

9. Zhou F, Yu T, Du R, Fan G, Liu Y, Liu Z, et al. Clinical course and risk factors for mortality of adult inpatients with COVID-19 in Wuhan, China: a retrospective cohort study. The Lancet. 2020.

10. [Internet].2020[cited6/28/2020].Available from:https://www.who.int/news-room/detail/11-05-2020the-cost-of-inaction-covid-19-related-service-disruptions-could-cause-hundreds-of-thousands-of-extradeaths-from-hiv.: World Health Organization; [.

11. Hogan AB, Jewell B, Sherrard-Smith E, Vesga J, Watson OJ, Whittaker C, et al. The potential impact of the COVID-19 epidemic on HIV, TB and Malaria in low-and middle-income countries. Imperial College London (01-05-2020) DOI: https://doi org/1025561/78670. 2020.

12. Gupta AG, Moyer CA, Stern DT. The economic impact of quarantine: SARS in Toronto as a case study. J Infect. 2005;50(5):386-93.

13. Warren DK, Shukla SJ, Olsen MA, Kollef MH, Hollenbeak CS, Cox MJ, et al. Outcome and attributable cost of ventilator-associated pneumonia among intensive care unit patients in a suburban medical center. Critical care medicine. 2003;31(5):1312-7.

14. Cheung AM, Tansey CM, Tomlinson G, Diaz-Granados N, Matté A, Barr A, et al. Two-year outcomes, health care use, and costs of survivors of acute respiratory distress syndrome. Am J Respir Crit Care Med. 2006;174(5):538-44.

15. Bartsch SM, Ferguson MC, McKinnell JA, O'Shea KJ, Wedlock PT, Siegmund SS, et al. The Potential Health Care Costs And Resource Use Associated With COVID-19 In The United States. Health affairs (Project Hope). 2020:101377hlthaff202000426.

16. Rapoport J, Teres D, Zhao Y, Lemeshow S. Length of stay data as a guide to hospital economic performance for ICU patients. Medical care. 2003:386-97.

17. Dasta JF, McLaughlin TP, Mody SH, Piech CT. Daily cost of an intensive care unit day: the contribution of mechanical ventilation. Critical care medicine. 2005;33(6):1266-71. 
18. Norris C, Jacobs P, Rapoport J, Hamilton S. ICU and non-ICU cost per day. Canadian journal of anaesthesia. 1995;42(3):192-6.

19. Wang D, Hu B, Hu C, Zhu F, Liu X, Zhang J, et al. Clinical characteristics of 138 hospitalized patients with 2019 novel coronavirus-infected pneumonia in Wuhan, China. Jama. 2020;323(11):1061-9.

20. Grasselli G, Zangrillo A, Zanella A, Antonelli M, Cabrini L, Castelli A, et al. Baseline characteristics and outcomes of 1591 patients infected with SARS-CoV-2 admitted to ICUs of the Lombardy Region, Italy. JAMA. 2020.

21. Oostenbrink JB, Buijs-Van der Woude T, van Agthoven M, Koopmanschap MA, Rutten FF. Unit costs of inpatient hospital days. Pharmacoeconomics. 2003;21(4):263-71.

22. Lee J-W, McKibbin WJ, editors. Estimating the global economic costs of SARS. Learning from SARS: preparing for the next disease outbreak: workshop summary; 2004: National Academies Press Washington, DC.

23. Rice DP, Hodgson TA, Kopstein AN. The economic costs of illness: a replication and update. Health Care Financ Rev. 1985;7(1):61.

24. Brahmbhatt M, Dutta A. On SARS type economic effects during infectious disease outbreaks: The World Bank; 2008.

25. Keogh-Brown MR, Smith RD, Edmunds JW, Beutels P. The macroeconomic impact of pandemic influenza: estimates from models of the United Kingdom, France, Belgium and The Netherlands. Eur J Health Econ. 2010;11(6):543-54.

26. McKibbin W, Fernando R. The economic impact of COVID-19. Economics in the Time of COVID-19. 2020;45.

27. Fernandes N. Economic effects of coronavirus outbreak (COVID-19) on the world economy. Available at SSRN 3557504. 2020.

28. Kabir M, Afzal MS, Khan A, Ahmed H. COVID-19 pandemic and economic cost; impact on forcibly displaced people. Travel medicine and infectious disease. 2020:101661.

29. Daroudi AZK, Nahvijou A, Zahmatkesh,Akbarisari A. A Review of Methods for Estimating Economic Burden of Cancer. Hakim Health Systems Research Journal. 2014;16(4):349-57.

30. Hartunian NS, Smart CN, Thompson MS. The incidence and economic costs of cancer, motor vehicle injuries, coronary heart disease, and stroke: a comparative analysis. Am J Public Health. 1980;70(12):1249-60.

31. Rice DP. Cost-of-illness studies: fact or fiction? The Lancet. 1994;344:1519-20.

32. The Cost of Air Pollution. Strengthening the Economic Case for Action. World Bank. Washington, DC: (c) World Bank: Institute for Health Metrics and Evaluation;; 2016.

33. Keshavarz K, Kebriaeezadeh A, Alavian SM, Sari AA, Dorkoosh FA, Keshvari M, et al. Economic burden of hepatitis B virus-related diseases: evidence from iran. Hepatitis monthly. 2015;15(4).

34. Islamic Republic of Iran Implied PPP Conversion Rate, LCU per USD. 2020 [7/27/2020]. Available from: https://www.quandl.com/data/ODA/IRN_PPPEX-Islamic-Republic-of-Iran-Implied-PPP- 
Conversion-Rate-LCU-per-USD.

Page 12/12 